\title{
Developing a Framework to Explore Local Researchers' Engagement with Global Academia: The Case of Vietnamese Social Sciences Scholars
}

\author{
Cuong Huu Hoang ${ }^{1,2} \&$ Trang Thi Doan Dang ${ }^{3}$ \\ ${ }^{1}$ Faculty of Foreign Languages, Ho Chi Minh City Open University, Ho Chi Minh City, Vietnam \\ ${ }^{2}$ Faculty of Education, Monash University, Melbourne, Australia \\ ${ }^{3}$ Graduate School, Ho Chi Minh City Open University, Ho Chi Minh City, Vietnam \\ Correspondence: Cuong Huu Hoang. E-mail: cuong.hhuu@ou.edu.vn
}

Received: Febraury 16, 2021

Accepted: March 12, 2021

Online Published: April 27, 2021

doi:10.5539/ass.v17n5p1

URL: https://doi.org/10.5539/ass.v17n5p1

\begin{abstract}
In recent years, local scholars have been playing an increasingly significant role in the global knowledge system. However, in the context of Vietnam, interaction and engagement between Vietnamese social sciences researchers (VSSRs) with the global academic world are limited despite efforts from the Vietnamese government and tertiary institutions. This study explores the barriers that prevent Vietnamese scholars engaging with the international academic community. Eighty-two Vietnamese scholars in various fields of social sciences responded to an online self-reporting questionnaire including 13 closed-ended and nine open-ended questions. The results show that various individual factors (e.g., the researchers' inadequate proficiency in English or limited research capacities), organisational factors (e.g., the lack of a supportive research environment, the lack of funding and resources, and unsupportive policies), and broader factors (e.g., political censors or the tradition of social research) could significantly influence VSSRs' engagement with global academia. The study underlines the need for in-depth scholar-centred research to understand the process in which local researchers, who are disadvantaged by their contextual factors, participate in the international academic community. More importantly, findings are used to develop a potential framework to study local researchers' academic engagement with global academia.
\end{abstract}

Keywords: Academic engagement, Vietnamese social sciences, global academia, research communities

\section{Introduction}

While a growing body of research has largely addressed academic engagement (Perkmann, Salandra, Tartari, McKelvey, \& Hughes, 2021), it is an underexplored area in developing countries such as Vietnam. Academic engagement (AE), in a broad sense, is conceptualised as "knowledge-related interactions" among researchers with non-academic organisations. Such interactions include for example, research collaboration, research contracts, consulting activities, and networking with practitioners (Perkmann et al., 2021, p. 1). Academic engagement, in research, can include, but is not limited to, publishing research findings, disseminating research papers at international conferences, and participating in international research projects. Although universities in Vietnam require lecturers to achieve a certain degree of $\mathrm{AE}$ to ensure their research has a significant contribution to the field, it is AE in research especially with global academia (research engagement with global academia) that seems to have challenged researchers in this context. Publications by Vietnamese academics in international journals have been quite modest in number as compared with those of their Asian counterparts. The evidence of this is that only three articles in the area of social sciences from Vietnam were published in Institute of Scientific Information of United States (ISI) journals in 2008 (Hien, 2010). In the last decade, although there has been an increase in the number of international articles published by Vietnamese social sciences researchers (VSSRs) (Vuong et al., 2018; Vuong et al., 2019), Vietnam's research publication is still modest considering its research potential and publication capacity.

Evidence from previous research (Hien, 2010; Nguyen, 2020; Turpin et al., 2015) shows that published articles in social sciences in Vietnam are limited even though this area is believed to play an important role in shaping and constructing human society. Gerke and Evers (2006), for instance, maintain that social science knowledge, as an essential part of the epistemic culture, creates "an image of society and social processes" (p. 8). Thus, the work 
of social science academics and scholars is very significant for the development of society and the engagement of researchers in the society and amongst themselves is essential for their research capacity development. However, research evidence from AE in the area of social sciences is inconclusive or limited (see the review in Perkmann et al., 2021). Furthermore, social sciences in Vietnam are somewhat left behind its counterparts in developed countries and Vietnamese social scientists are still underrepresented nationally and internationally (Hoang, 2021). This provides an impetus for conducting the present research into barriers for Vietnamese scholars' engagement with the international academic community.

This study used an exploratory approach to understand the experience that VSSRs had when engaging with global academia via three main channels: disseminating research through publication, presenting research in international conferences, and participating in international research projects. The findings reported in this article are preliminary data from a doctoral research project on the discursive identities of Vietnamese social science scholars in Vietnam and the diaspora, aspects of which have been published by Hoang (2021), Hoang and Nguyen (2021), Hoang and Turnner (2000), and Hoang (2015). Although this study adopted an exploratory design framed by a grounded theoretical approach, the findings were used to develop a framework to explore researchers' engagement with global academia. To foreground the discussion of this framework, the article starts with an introduction about social sciences in Vietnam. The nature of the local researchers' engagement is then framed from a broader context of an interconnected local-global knowledge relationship. After that, the research method and findings sections are structured to answer the three explorative research questions. Finally, the discussion section discusses the findings in relation to the presented literature and proposes a framework for future research on academic research engagement in other countries.

\section{Social Sciences in Vietnam}

Social sciences and humanities in Vietnam were formed on the foundation of Confucian institutions, Buddhism, Taoism, French colonial heritage and Communist ideology. These various ideologies and institutions have shaped the way Vietnamese people interpret and reflect on their social issues. On the one hand, this circumstance can provide Vietnamese researchers with rich foundations and various approaches toward social knowledge. On the other hand, it might influence the researchers' work, especially when these different ideologies did not fully develop into grand theories and reach their peak in Vietnam. Vietnam social sciences might suffer the same theoretical deficit as other Asian countries. Clammer (2000) discussed how, despite cultural specificities and their status being an interesting subject for international scholars, Asian societies have not produced a "high theory" for themselves. They often have to depend on Western or Eurocentric knowledge (which has, to a certain extent, been considered as "universal knowledge") due to the process of colonisation, intellectual imperialism, the forces from Western societies to modernise as well as the globalisation process (Selvadurai, Choy, Maros, \& Abdullah, 2013). Nevertheless, with a long history of development and an East-West fusion background, social science in Vietnam has a great potential to become a strong area of study.

The modern social sciences in Vietnam have been strongly influenced and orientated by the national Communist Party. The government has implemented several policies to guide social science activities which, despite affirming the attention of the government to the development of social sciences, indicate the "top-down" regulation and Communist line direction towards social science activities. For instance, the Resolution 51-HDBT states that social sciences must "focus its research on the problems regarding economic and social management aimed at promoting socialist transformation and restoring socialist order" (Ho, 1987, p. 136). According to Ho (1987), social sciences were aimed to assist the ideological and cultural revolution. Hence, research projects in social sciences used to revolve around the main theme of developing a socialist country and have been relatively restricted in their contents and approaches.

The research activities in social sciences in Vietnam have been largely oriented in accordance with socialist precepts. Social sciences subjects are taught at a variety of universities where these subjects are directed by the state leadership. There are a large number of research institutes focusing on or orientated by Communist ideology such as the Ho Chi Minh National Institute of Politics, National Institute of Politics, Politics Institutes for Vietnamese People's Police and other state-funded organisations like the Historians' Association, the Economists' Association or the Folk Cultural Workers' Association. Being founded and funded by the state, the research activities carried out by these institutes and organisations are supposed to contribute to "the building of socialism and defence of their socialist motherland" (Ho, 1987, p. 140). These boundaries could perhaps limit voices from different groups of people who want to critically investigate the efficiency of the state as well as to critically discuss some theoretical issues that do not fit with the accepted ideology. However, in recent years, thanks to the Open Door policy in 1986 as well as the globalisation in education especially internationalisation of higher education in Vietnam, VSSRs have been able to use various research approaches to conduct research on a 
wide range of topics in social sciences - some of which used to be regarded as sensitive and controversial.

Nevertheless, the development of social sciences at Vietnamese higher institutions has not been remarkable. Although Vietnamese universities have proliferated in recent years with many practical courses such as business, economy, and tourism, the development of social sciences in Vietnamese higher institutions is much less impressive (London, 2013). London discussed that this might directly result from Vietnam's political economy in which social sciences are largely subordinated by the state interest. Hence, social science research productivity is often policy-driven. The research production of Vietnam in the field of social sciences before 2000 was recorded as very low especially when compared with other ASEAN countries like Thailand, Malaysia, and the Philippines. The dilemma is that although Vietnam received a much higher global output than most ASEAN countries before 2000, the local contribution of Vietnamese scholars to global knowledge was very small (Gerke \& Evers, 2006). This trend was in contrast with Singapore which only received minimal interest from international social scientists while their local contribution to world knowledge was greater than that of Vietnam. This dilemma of Vietnamese social science partly revealed the knowledge dependence of Vietnam on outside sources.

The development of Vietnam's social sciences and their contribution to world knowledge are considered limited despite being regarded as an interesting topic of research (Gerke \& Evers, 2006; 2010). For this reason, this study seeks to gain an understanding of the VSSRs communities as well as the challenges they face when engaging with the global academic community.

\section{Global and Local Knowledge}

\subsection{The Interconnected Relationship between Global and Local Knowledge}

Local knowledge refers to the knowledge specific to a nation (Lord \& Ranft, 2000) or knowledge that is "unique to a given culture or society" (Warren, Brokensha, \& Slikkerveer, 1991, p. 1). Such knowledge is often embedded in a culture and contextually dependent ( $\mathrm{Li}$, Easterby-Smith, Lyles, \& Clark, 2006). It often describes the social capacities in addressing issues and providing solutions which do not belong to the globally dominant pattern but relate to "a geographically or socially limited spread" (Renn, 2012, p. 369). On the other hand, global knowledge refers to the knowledge systems and methodologies which are "developed, codified, and institutionalised in the context of the modern West" (Tauxe, 2009, p. 122). These knowledge systems and methodologies are internationalised and accepted as "the standard of rational thought on how things really are" (Tauxe, 2009, p. 122). This codified knowledge has then been able to travel the world thanks to the globalisation process, especially the advances in information and communication technologies (Bathelt, Malmberg, \& Maskell, 2004).

The interplay between local and global knowledge has been described as mutually interdependent and interconnected ( $\mathrm{Li}$ et al., 2006). The exchange of knowledge between the two systems is believed to have lasted for more than a century thanks to the globalisation process (Gough, 2002) and thus the local and international knowledge are naturally inclusive and "socially and historically constructed" (Akpan, 2011, p. 125). Knowledge not only comes from the academic centers in the Western hemisphere but also from countries such as China, India, and South Korea (Hébert \& Abdi, 2013). In many fields of study, researchers have discussed the importance of "thinking globally, acting locally" and argued for the significance of the connection of local knowledge with global knowledge. For instance, in the field of environmental education and science, Gough (2002) believed that Western science should be enforced by local knowledge traditions to understand and resolve environmental issues. In other words, the development of society needs both local knowledge and knowledge from outside.

From a business perspective, $\mathrm{Li}$ et al. (2006) identified three interactive modes to capture the relationship between global and local knowledge: global penetration, local-global bending, and local-global integration. Firstly, global knowledge penetration indicates that the global knowledge system creates a platform for local communication in which the direction of knowledge movement is one way: from global to local. The second mode involves expanding the cooperative common knowledge base so that it experiences two ways of knowledge movement: from local to global and vice versa. With this mode, global knowledge can be used for local contexts and local knowledge can be transferred into global knowledge. The third model considers local knowledge as a significant component of global knowledge and the relationship between global and local knowledge are interdependent. This model explores the full value of local knowledge because it posits the local knowledge in the centre and as an essential part of global knowledge.

Overall, global and local knowledge are discussed as integrated and cooperatively constructed. Various perspectives and frameworks have tried to combine the global with local knowledge, the knowledge from the East with the West, and other places in research. Although the hierarchical relationship between the two systems 
is inherent in various platforms and contexts, the integration of knowledge has become increasingly significant in the modern world.

\subsection{Knowledge Exchange in the Global Academia Platform and Academic Engagement}

The process of globalisation and internationalisation in higher education has significantly contributed to the production of knowledge in higher education platforms and especially the exchange of knowledge. Globalisation in higher education brings opportunities for academics to learn, to connect, and to collaborate with their international peers (Altbach, 2004). Higher education institutions at the academic centre in developed countries become essential components of the global knowledge network and many of those from the periphery try to participate in this network in various ways. In addition, information technology helps to not only store and search for scholarship but also assist learning, researching, and teaching activities. The international knowledge network becomes a central aspect of academia thanks to the Internet, the increased use of English in science, and the closer connections between academic institutions (Altbach, 2013). Finally, the publishing industry and knowledge ownership worldwide require researchers from higher educational institutions to strive for better-qualified research articles.

As mentioned in the introduction, a great number of studies have been conducted on the topic of $\mathrm{AE}$ between academics and outsider organisations (Perkmann et al., 2021). Perkmann shows that AE is decided by individual characteristics, institutional contexts and organisation and relational contexts. First, AE is largely influenced by individual motivations and attributes rather than by universities' characteristics (Lam, 2011; Tartari \& Breschi, 2012). Second, the relational context (especially peer effects) and organisational context (such as organisational support, incentives) can positively influence AE (e.g., departmental peers' engagement encourages junior faculty members to engage with the industry (Tartari, Perkmann, \& Salter, 2014) or mobilising research funding and resources encourages research engagement). Third, the institutional context, especially disciplinary affiliation, regulations, and policies, can play significant roles in shaping AE activities (Perkmann et al., 2021). These three overarching groups of factors decide research productivity, quality and the societal and economic impact of research.

However, so far research on EA has been centred mainly on the AE activities of academics from hard science backgrounds and universities in the global north, focusing more on the engagement between academics and industry. Not many studies have been conducted on research engagement of social science scholars from the global south in their process of engagement with global academia. Thus, it can be assumed that factors influencing global south academics' engagement with the global academic community can be very different from what Perkmann et al. (2021) described. Given the recent strong knowledge exchange amongst institutions and academics, especially between those from the developing countries with developed ones, a study on the experience and difficulties that acadmics in developing countries have when engaging with global academia is of paramount importance.

\section{Research Method}

This article uses a self-reporting questionnaire extracted from a larger study to explore the experiences of VSSRs in engaging with global academia through three channels: publishing their research, disseminating their research in international conferences, and involving themselves in international research projects. The self-reporting questionnaire was used to obtain an overview of the Vietnamese scholars' backgrounds, their experiences with peer-reviewed publications, research collaboration, and conference presentations. According to Harris and Brown (2010), questionnaires can "provide evidence of patterns amongst large populations" (p. 1). The use of a questionnaire not only provided a sketch of a Vietnamese scholars' community but also revealed some patterns within this community. The patterns discovered helped the researcher learn about the researched phenomenon.

Since the questionnaire was considered a preliminary investigation to gain an understanding of the community of VSSRs, it aimed to answer broad questions about this community as well as providing space for researchers to share their personal experience in engaging with the global academic community. The research questions were to gain understandings about who the VSSRs were and the challenges they faced when engaging with global academia. Assuming the English language and research skills to be important factors, the study also asked participants to self-evaluate their academic English competence and research skills. The research questions are as follows:

1. Who are the Vietnamese social science scholars aspiring to engage with global academia?

2. How do they evaluate their academic English and research skills?

3. What are the challenges that they face when they interact with global academia through three channels: 
1. participating in international research projects,

2. presenting research results at academic conferences,

3. and publishing in international peer-reviewed journals and edited books?

As an exploratory investigation, the study did not limit the number of participants as long as they met the basic criteria of the study - VSSRs who were working or had worked in Vietnam. Potential participants were invited to join the research through an email letter explaining the research and containing the link to the online questionnaire. Their email addresses were sourced in two ways: via their online profiles and other publicly available websites and through a snowballing technique. The snowballing strategy involved identifying cases of interest from sampling participants who knew people who shared similar characteristics with other possible sampling participants (Patton, 2002). This technique helped to recruit the participants who met the criterion of the study. Those who chose to participate were asked to forward the information to other potential participants. Despite the researcher's attempts to involve as many participants as possible, the number of participants was small and could not represent the entire community of Vietnamese scholars. Hence, instead of providing a general picture of the entire community of VSSRs, the study provides detailed descriptions of those who agreed to be involved in the study and had a strong desire to participate in the global academic community.

For the participants' recruitment, two main ethical issues, namely confidentiality and anonymity, and power relations, were addressed carefully during the design and resultant reporting stages. These two aspects were managed by ensuring that the questionnaire was anonymous, online-based and that no personal questions were asked. Hence, the anonymity and confidentiality were safeguarded because there would be no way to track down which questionnaire response belonged to whom unless the respondents chose to be contacted for the second stage. In terms of power relations, the online questionnaire caused no power relation conflicts since our respondents were independent researchers and, hence, they were well aware that their participation or non-participation would not cause problems or affect them in any way, especially when we (the authors) and the participants did not know each other before the research. In addition, the invitation emails included explanatory statements and the ethical approval document, which explained clearly the purpose of the study, the anonymity of the questionnaire and the voluntary nature of the research.

The questionnaire was written in both English and Vietnamese and the participants could choose the language in which they felt most comfortable to respond. The questionnaire, which was developed conceptually, statistically analysed, and embedded in the Qualtrics software, including 13 closed-ended multiple-choice questions and 9 open-ended questions. The closed-ended questions focused on factual information such as the number of publications, the ranking of the challenges influencing their research job and international engagement, and their number of teaching and researching years. The open-ended questions asked participants to reflect on their research experience in conducting research in Vietnam and especially their research engagement experience with global academia.

The open-ended questions in the questionnaire, aiming to collect participants' perceptions of experience and challenges when conducting research in Vietnam, were analysed qualitatively. The approach to understanding these data was content analysis (Vaismoradi, Turunen, \& Bondas, 2013). This method refers to the use of systematic coding to explore a great deal of textual information to identify trends, patterns, frequency, structure and the relationships of words used in the data set (Vaismoradi et al., 2013). Following the work of Perkmann et al. (2021) the challenges listed by participants were grouped into three main categories: personal characteristics, organisational contexts, and broader contexts. This aimed to develop a distinct way to classify codes and patterns in participants' responses to frame these challenges in a logical way.

\section{Findings}

Findings are presented to answer the three research questions sequentially. When possible, responses from different groups of participants are compared and underlying implications are drawn.

\subsection{Research Question 1. Who Are the VSSRs?}

\subsubsection{Participants' Demographic Information}

After three months of posting the questionnaire through online channels, responses of eighty-two Vietnamese researchers from various fields in social sciences were collected. The questionnaire did not result in an equal distribution of researchers across different fields although the study utilised the snowballing technique, and the researchers responded to the questionnaire via emails, research groups, and academia forums in Vietnam. The participants with qualifications of Teachers of English to Speakers of Other Languages (TESOL) outnumbered those in the fields of education, literature and anthropology, history, and public relations. This might be 
explained by the fact that we had been in contact with some participants in these fields through our common educational background. As such, there might have been some bias in the results, and that required caution when interpreting the data.

Tables 1 and 2 show the biographical data and academic background of participants. These demographics have been previously discussed in Hoang (2015).

Table 1. Distribution of Participants

\begin{tabular}{ccccccc}
\hline & \multicolumn{2}{c}{ Age range } & \multicolumn{2}{c}{ Gender } \\
\hline & $<25$ & $25-35$ & $35-45$ & $>45$ & Male & Female \\
\hline Number of participants & 4 & 48 & 26 & 4 & 30 & 52 \\
\hline
\end{tabular}

Table 2. Participants' Education Background

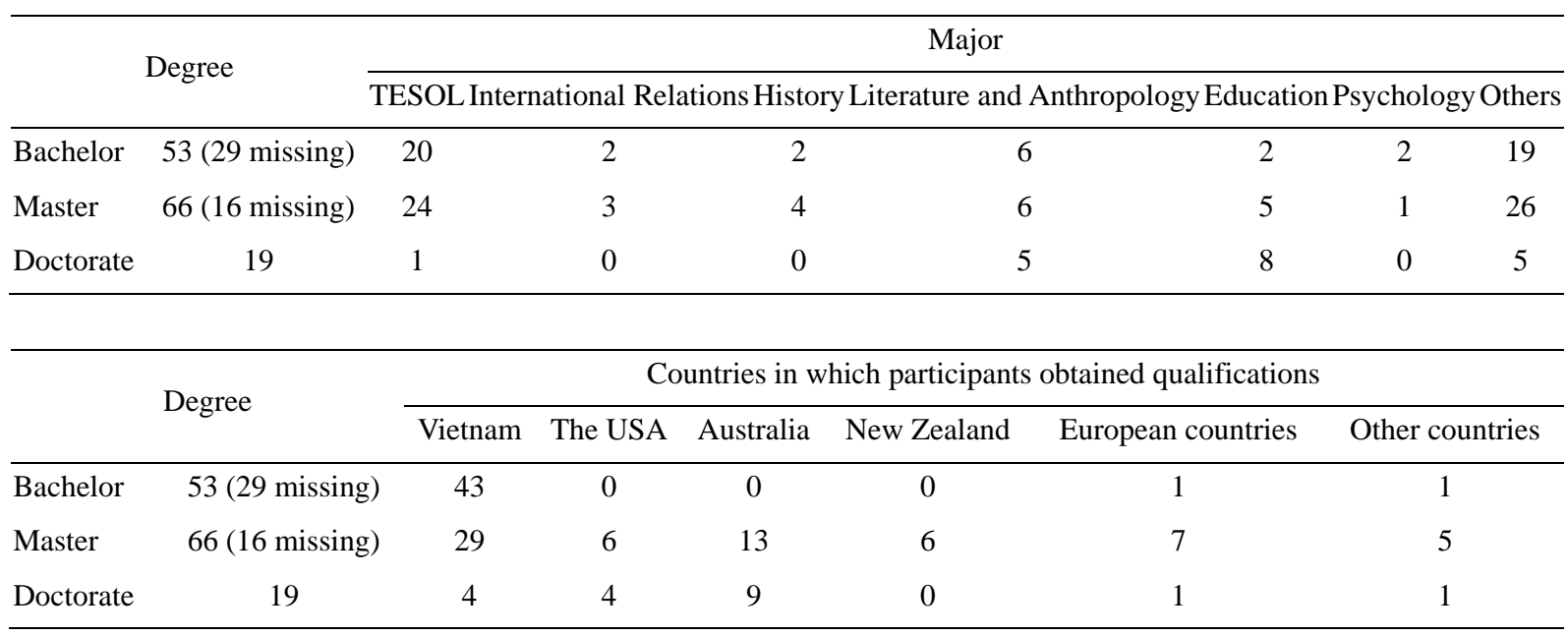

Table 1 clearly shows that most respondents, aged from 25 to 35, are early-career researchers. Table 1 reveals that female participants outnumbered their male correspondents. It can be seen from Table 2 that most participants obtained their Bachelor qualifications in Vietnam $(\mathrm{N}=53)$. Among the 66 respondents having Master degrees, 37 participants $(56 \%)$ obtained their qualification in a Western country, most commonly including Australia, the United States of America and New Zealand. There were also nineteen participants who had finished or conducted their doctoral studies in other areas, but education, literature, and anthropology were the most popular fields.

The follow-up, open-ended question revealed that participants from other fields of social sciences listed a wide range of fields that interested them. For instance, one participant majoring in international relations showed his interest in human rights, social policies and human ecology. Another participant who specialised in journalism expressed her research interests in media, power, nationalism and the theories of Foucault. The variety of participants with different research interests is beneficial as voices from different fields of social sciences were able to be represented. The results indicate that VSSRs have a wide range of research interests and can shift between different juxtaposing topics.

Nearly seventy per cent of participants $(n=57)$ are employed in tertiary institutions while the rest $(n=16$; missing =9) work in NGO organisations, research organisations or the field of publication. It can be seen from Figure 1 that the teaching experience and researching experience of the participants have varied: from zero to 24 years of teaching experience and from one to 40 years of researching experience. The participants' years of teaching and researching are divided into seven different groups as represented in the horizontal axis.

It can be seen from Figure 1 that participants who had from 1-5 years of experience in lecturing and researching represented the largest age-range group. Among 73 participants with experience in conducting research, two respondents had experienced more than 25 years of research while other participants are early researchers and lecturers, which may affect the quality of their academic research. Although they had been working as early lecturers, their engagement with the academic community is evidence of active and potential researchers. 


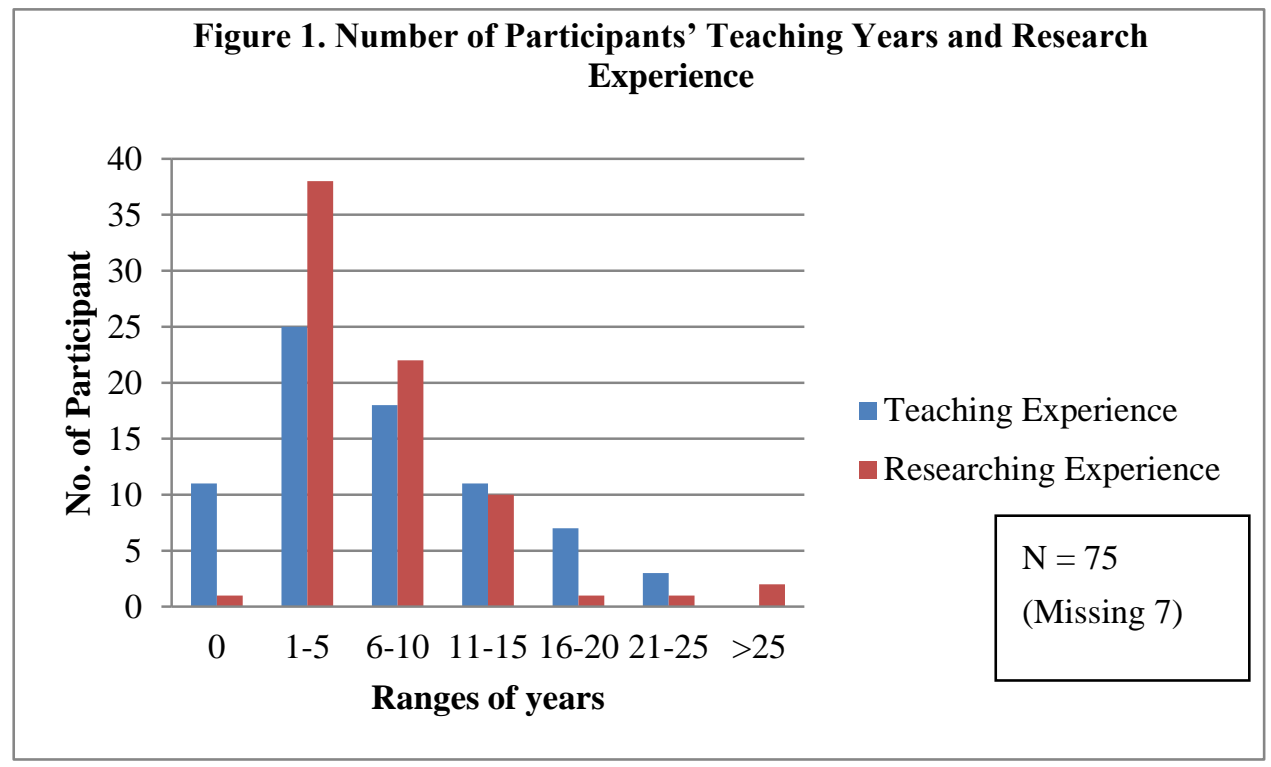

Regarding language skills, all respondents self-identified that they were able to use English while some were able to use Chinese $(n=4)$, Russian $(n=3)$, Japanese $(n=2)$, German $(n=1)$ and French $(n=1)$. The profile of participants clearly reveals that they came from various research backgrounds; most were early career researchers while the majority were experienced ones.

\subsubsection{Participants' Research Outcomes}

The results shown in Table 3 below report participants' research outcomes. These data, which were previously presented in Hoang (2015), have been expanded to reflect more details relevant to the present reporting of the study.

Participants' responses to the questionnaire show that they had had quite limited interaction with global academia in terms of publishing, conferencing and participating in international research projects. Many researchers responded that they had not had any of these experiences.

Table 3. Number of Participants' Research Outcomes

\begin{tabular}{|c|c|c|c|c|c|c|}
\hline \multirow[t]{2}{*}{ Question } & \multicolumn{4}{|c|}{ Number of research outcomes } & \multirow{2}{*}{ Total Responses } & \multirow{2}{*}{$\begin{array}{l}\text { Mean of } \\
\text { four groups }\end{array}$} \\
\hline & 0 & $1-3$ & $4-5$ & $>5$ & & \\
\hline $\begin{array}{l}\text { Number of research projects funded by the Vietnamese } \\
\text { government in which you have been involved }\end{array}$ & 31 & 31 & 5 & 10 & 77 & 1.92 \\
\hline $\begin{array}{l}\text { Number of research projects funded by foreign } \\
\text { organisations in which you been involved }\end{array}$ & 33 & 39 & 3 & 1 & 76 & 1.63 \\
\hline $\begin{array}{l}\text { Number of articles that you have published internationally } \\
\text { in peer-reviewed journals }\end{array}$ & 52 & 19 & 3 & 2 & 76 & 1.41 \\
\hline $\begin{array}{l}\text { Number of articles that you have published internationally } \\
\text { in edited books }\end{array}$ & 53 & 21 & 0 & 2 & 76 & 1.36 \\
\hline $\begin{array}{l}\text { Number of articles that you have published domestically } \\
\text { in peer-reviewed journals }\end{array}$ & 22 & 33 & 13 & 8 & 76 & 2.09 \\
\hline $\begin{array}{l}\text { Number of articles/book chapters that you have published } \\
\text { domestically in edited books }\end{array}$ & 43 & 23 & 4 & 4 & 74 & 1.58 \\
\hline $\begin{array}{l}\text { Number of academic articles submitted for publication in } \\
\text { an international journal being rejected }\end{array}$ & 58 & 15 & 0 & 1 & 74 & 1.24 \\
\hline $\begin{array}{l}\text { Number of academic articles submitted for publication in } \\
\text { domestic journal being rejected }\end{array}$ & 58 & 16 & 1 & 0 & 75 & 1.24 \\
\hline Number of international conferences organised overseas at & 29 & 29 & 10 & 10 & 78 & 2.01 \\
\hline
\end{tabular}


which you have presented

Number of domestic conferences at which you have presented

25

33

9

12

79

Number of international conferences organised in Vietnam at which you have presented
29
78
1.95

It can be seen from Table 3 that a majority of the VSSRs did not have either experience in international research projects (33 participants) or internationally published peer-reviewed journals or edited books (52 and 53 respectively). Neither had they presented in international conferences organised overseas or in Vietnam (29 and 29 respectively). It can be inferred from the data that participants might not yet have been very active in their research.

The participants' research outputs have been recognised in global academia. However, the number of peer-reviewed publications and published chapters in edited books is lower than that of local publications. The analysis in Table 3 shows that the international peer-reviewed publications have higher means than those of local publications: 1.41 for international peer-reviewed journals, 1.36 for international edited books, and corresponding types of domestic publications 2.09 and 1.58 respectively. Two respondents had five (or more) academic papers published in international peer-reviewed journals. The higher means values reflect that the participants were more involved in domestic research projects than in international projects. Overall, their participation in academia is still quite limited.

\subsubsection{Participants' Commitment and Desire to Engage in Global Academia}

The responses to the open-ended question on their research engagement plan showed that more than 90 per cent of participants said that they expected to publish their study in an international peer-reviewed journal, to attend international conferences and to take part in international research projects. However, they also mentioned various difficulties that they needed to overcome. These difficulties are analysed in respect of research question 3 .

\subsection{Research Question 2: How do They Evaluate Their Academic English and Research Skills?}

Figure 2 presents the results of participants' self-assessment of their English language competence. Respondents felt confident in their English competence; however, it should be noted that a large number of participants have a TESOL qualification. Therefore, they were more confident with their English competence than other groups of participants. The skill that most participants felt most confident in was reading, while speaking was their least confident skill. The variance also showed that reading had the smallest variance while speaking had the highest. Figure 2 provides participants' self-assessment on their English academic competence. The number in the table is the number of responses for each item.

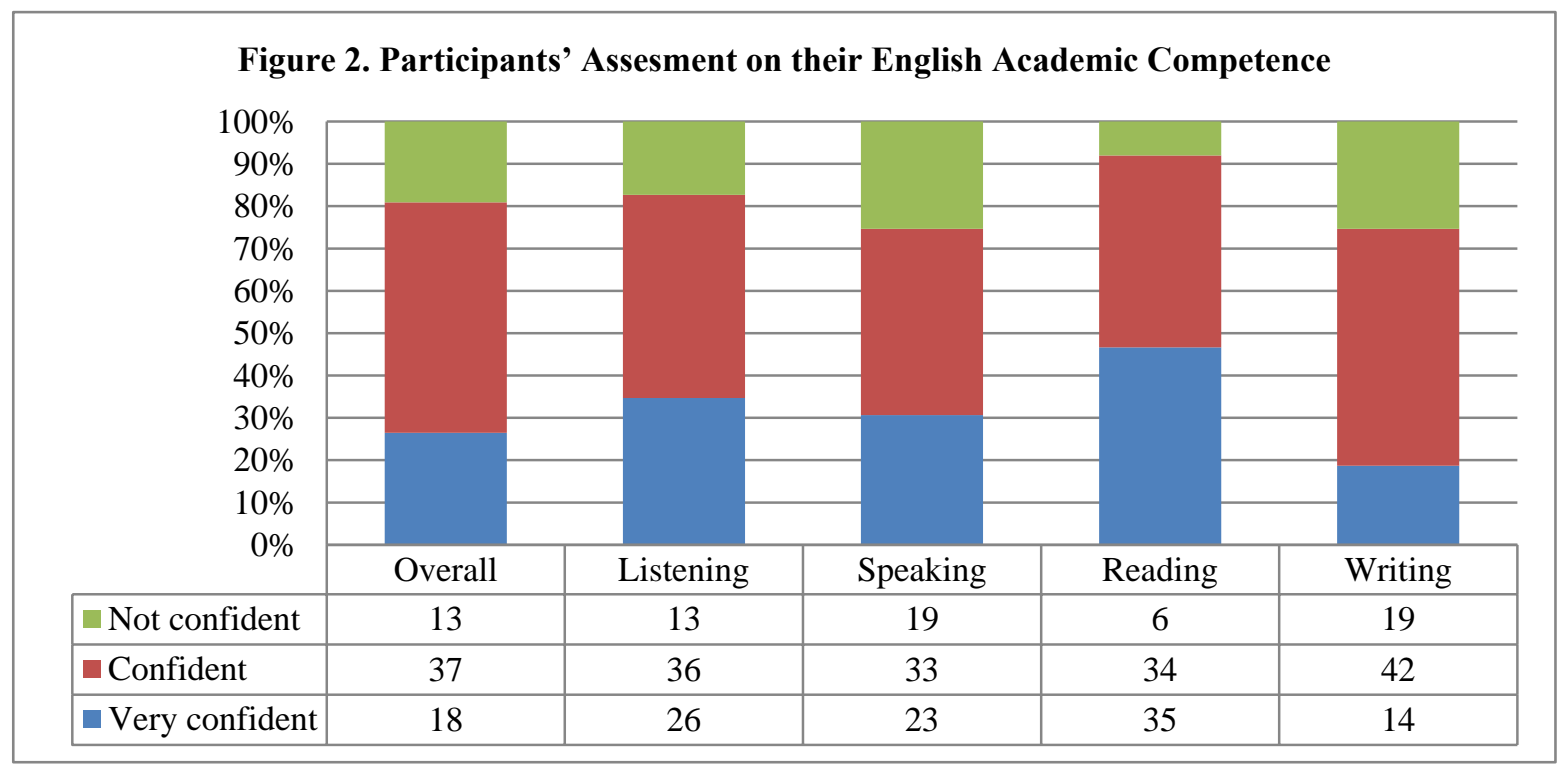


When asked in the follow-up open-ended question about the number of English articles in their fields that participants read per year approximately, 23 participants claimed that they read fewer than 10 articles per year. On average, participants read approximately 30 articles per year, a number that seems to be quite modest for an active researcher. The two most reported reasons for the infrequency of reading English articles were their inability to access international peer-reviewed articles (67\%) and the inability to allocate time for reading (61\%).

The analysis in Figure 3 below shows different levels of engagement with aspects of research skills. The research question on participants' confidence in carrying out research shows that the participants were most confident in collecting and analysing data. They were less confident in writing up their findings and designing a research study. Figure 3 shows participants' self-evaluation of their confidence in conducting different aspects of a research project.

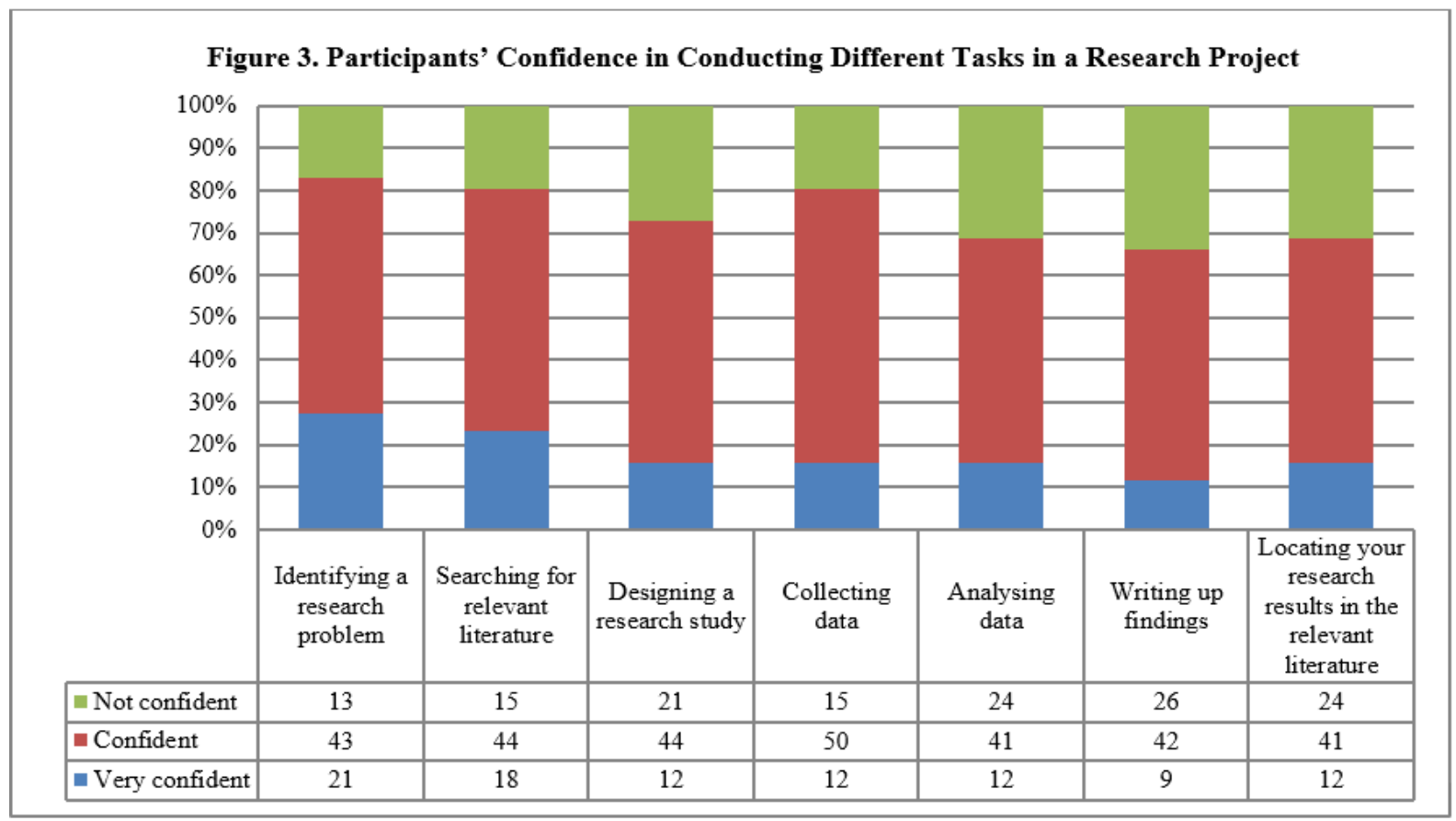

The responses to these questions suggest that English or limited knowledge of research skills might not be the only barriers preventing social researchers from Vietnam from engaging with global academia.

\subsection{Research Question 3. What Are the Challenges That They Face When They Interact with Global Academia?}

Given the aim of investigating the participants' challenges, the questionnaire was designed to ask the participants to list five challenges that they had faced and overcome during their engagement with the global community. In addition, the participants were also asked to rank some given challenges.

\subsubsection{The Challenges When Participating in International Research Projects}

Participants responded that when participating in international research projects, the most considerable challenges for Vietnamese scholars included personal characteristics (English competence, research experience/skills, limited connections) and organisational factors (limited funding, lack of institutional supports, and professional development training). English language proficiency was given as the foremost personal reason followed by research experience, communicative issues, high expectations of their Western peers, information on the projects and networks of researchers. In addition, a number of participants were concerned about their lack of research ability and skills and confidence to become involved in international research projects to meet international standards. Second, participants responded that they rarely received support from their employers, especially in terms of funding, to participate in these projects. They also pointed out that they had not had opportunities to keep up with research trends at a global level (partly due to the lack of research development programs and support). Interestingly, three participants reported that limited connections with other researchers and research communities was one of the significant challenges.

Figure 4 indicates the participants' 10-rating score scale of challenges for VSSRs to participate in international research projects. A significant challenge was equal to ten while zero was equal to not being a challenge for them. Below are results described as standard deviation and average value. 
Figure 4. Rating of Challenges for Participating in International Research Projects (10-score scale)

- Standard deviation $\quad$ Average value

Not available in your country

Limited language competence (English)

Lack of research experience

Lack of knowledge of the field

Lack of information on research projects

Lack of financial resources

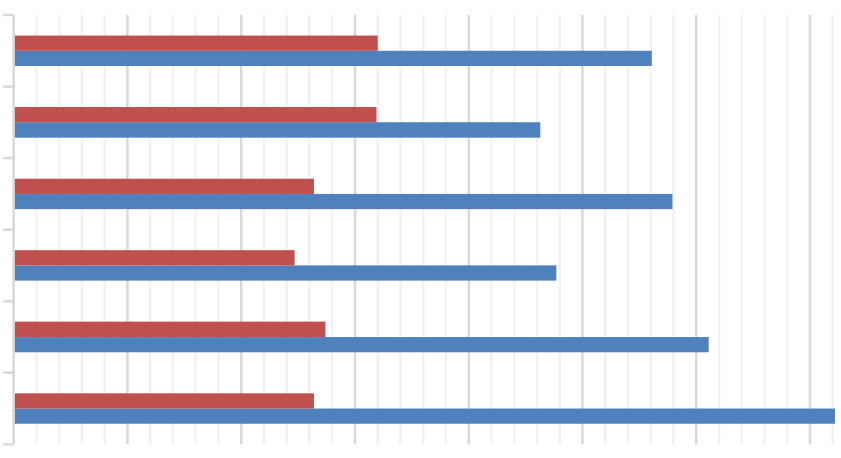

$\begin{array}{llllllllll}0 & 1 & 2 & 3 & 4 & 5 & 6 & 7 & 8\end{array}$

Figure 4 shows that a shortage of finance is ranked as the most significant challenge for researchers participating in international research projects. In contrast, English competence only scored 4.5 (on average) on the 10-rating score scale for challenges. Limited English competence also had the highest standard deviation (3.31). This means that participants gave it either a very high or a very low score. The participants might be either fluent in or not very influent in their English, as a large number of participants in the study have TESOL qualifications. The statement that international research projects may not be available in Vietnam can indicate either the small number of international research projects in social sciences in Vietnam or the participants' lack of information about these projects.

\subsubsection{The Challenges-When Presenting Their Research at International Research Conferences}

\section{Figure 5. Rate of challenges for presenting at international conferences (10-} score rate)

\section{- Standard deviation Average value}

Lack of professional presentation skills/ experience

Lack of language competence (English) to present at international conferences

Lack of information about conference in your field

Lack of support (time, finance, incentive etc.) from employer

Limited research findings

Lack of financial support

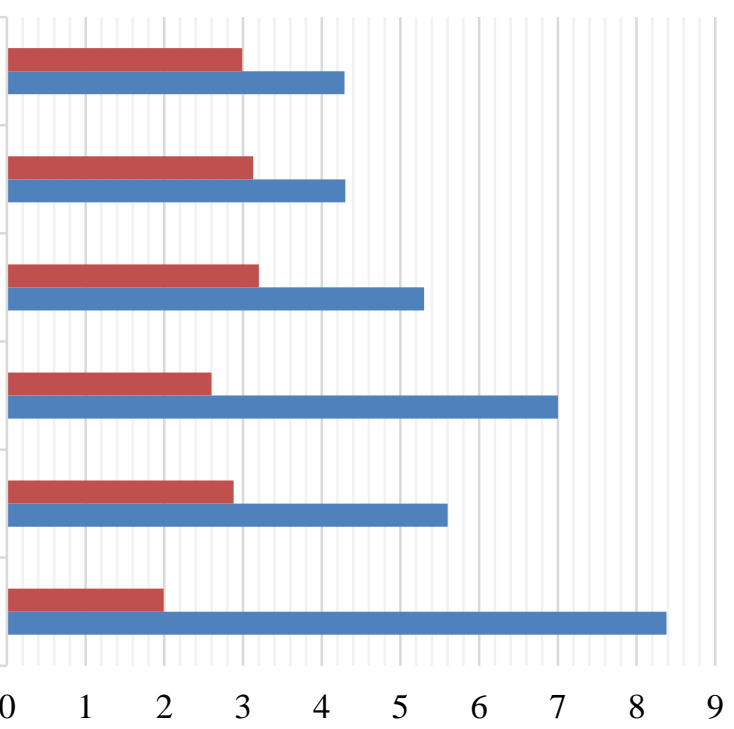

Participants responded that two organisational and relational context factors (funding and support in terms of time), four individual attributes (English competence, presentation skills, family support, lack of information), and one broader factor (political censorship) were main challenges for their participation in international research conferences. Funding and supports were the two most prominent challenges that all participants perceived. Many participants $(80 \%)$ responded that they had not received employer support in terms of finance 
or time. This challenge was followed by English competence and presentation skills; for example, they were concerned about their ability to speak to a large audience or to disseminate their research in an international context. Lack of family support, long hours of work, and difficulty finding information about the conferences in their field were also added. Some participants stressed that they could not find prestigious conferences in their field or the right audience for the topic of their research. They found difficulty finding audiences who are familiar with the context of Vietnam. In addition, one participant acknowledged that his research topic was "politically sensitive" and hence he did not want to present on it.

Figure 5 indicates the participants' 10-rating score scale of challenges for VSSRs to present their research at international conferences. Ten was equal to a significant challenge while zero was equal to not being a challenge for them. Results are presented as average value and standard deviation.

The ranking of challenges was consistent with the listed challenges for presenting at international conferences. Lack of financial support, which had the smallest standard deviation, was marked as the most significant challenge (8.38/10). Lack of support from the employer came second. Different from results from the earlier listing question, the quality/quantity of research was scored 5.38, higher than the rest of the reasons given. English competence, however, was ranked as the second least significant challenge.

\subsubsection{The Challenges When Publishing their Research in International Academic Journals or Edited Books}

\section{Figure 6. Rate of challenges for publishing internationally (10-score rate)}

$$
\square \text { Standard deviration } \square \text { Average value }
$$

The quality of your research findings is limited

You lack information on journals and their requirement in your field

Your employer does not support (e.g. time, fund, incentive) this aspect of your work

It is difficult to get access to updated knowledge in your field

You are not familiar with accepted norms of research reporting in English

You are not sufficiently competent in writing academic English

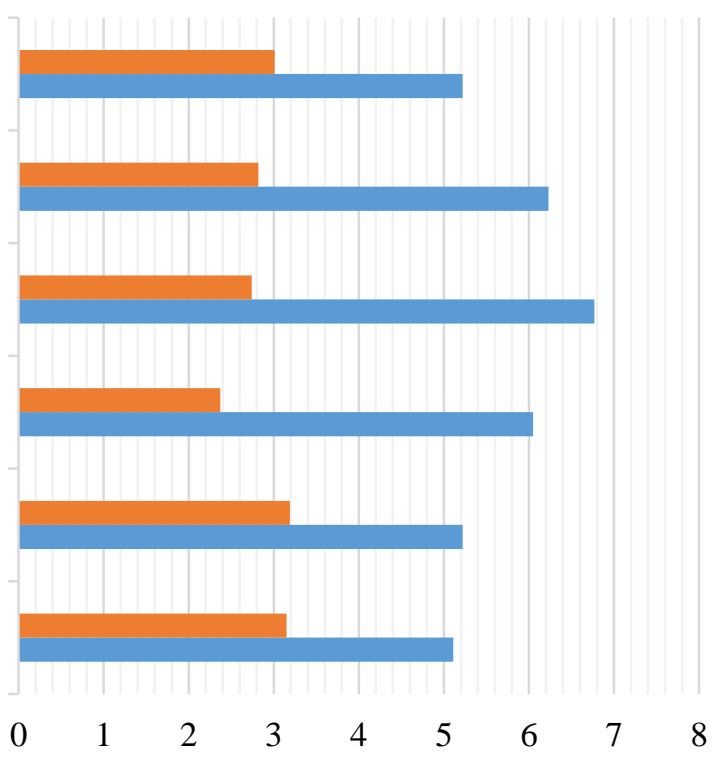

Similar to the challenges for participating in international research projects, individual characteristics (English capacity, research capacity, and publication quality) are mentioned as the most important barriers, followed by organisational factors (institutional supports, incentives, and resources as well as research-support colleagues) and broader factors (disciplines and research traditions in social science). First, participants' responses to the open-ended questions indicated that English competence (and English writing skills specifically) was the most popularly-listed challenge in publishing internationally. They perceived that they were unsure about the quality of their research due to the "theoretical inadequacy" and their limited knowledge of research methodology. They further expressed their concerns about the originality and the novelty of their study, and whether their research could have any impact on the theoretical framework or whether they had critical arguments on the issue investigated. Second, responses also indicated that participants did not receive support from their employers to engage in the global academia in ways such as research publications and dissemination. Given the fact that the employer did not acknowledge AE, a participant noted "there is no difference between international publication and domestic publication". The respondents also acknowledged that they had lacked access to potentially well-esteemed and high-ranking journals and they doubted the quality of peer-reviewed journals published in Vietnam which are often regarded as being of limited quality and lacking in authenticity. Others believed that the 
academic environment in Vietnam did not provide them with the opportunities to share and cooperate with their peers. They had no communities of researchers who could support and give them feedback. Third, approximately one in five participants thought that differences in academic cultures and research traditions in social sciences caused it to be harder to publish internationally.

Figure 6 indicates the participants' 10-rating score scale of challenges for VSSRs in publishing their research in international peer-reviewed journals and edited books. Ten was equal to a significant challenge while zero was equal to not being a challenge for them. Average value and standard deviation are presented.

It can be seen from the chart that lacking support from the employer is the greatest challenge the participants faced. Limited information on journals as well as access to knowledge in their field also challenged the VSSRs. However, research quality and English writing proficiency were acknowledged as being the least significant challenges, although writing research reports for peer-reviewed journals was considered more challenging than English writing competence itself. Some participants believed that their field of study had not developed in Vietnam so they did not have many opportunities to update themselves with recent developments in their field.

\section{Discussion and Recommendations}

The findings provide a snapshot of VSSRs' community through the sketch of the scholars who had a strong desire to engage with the global academia. Most participants formed part of the younger generation of researchers with limited research experience and research outcome but good English competence and a strong desire to engage with the global academic community. The findings indicate that the VSSRs had to cope with a wide range of challenges when they interacted with global academia. The study identified four organisational and relational contextual factors (including institutional research policies, funding and resources, research communities, and professional programs) that influence VSSRs' engagement with global academia. It also found three influential individual factors (research skills/experience, family support, and foreign language competency) and three broader contextual factors (research traditions, disciplinary characteristics, and political supervision) that are important to VSSRs' research engagement with global academia. The factors are presented in the following figure, which is an adaptation of the analytical framework of AE presented by Perkmann et al. (2021, p. $8)$.

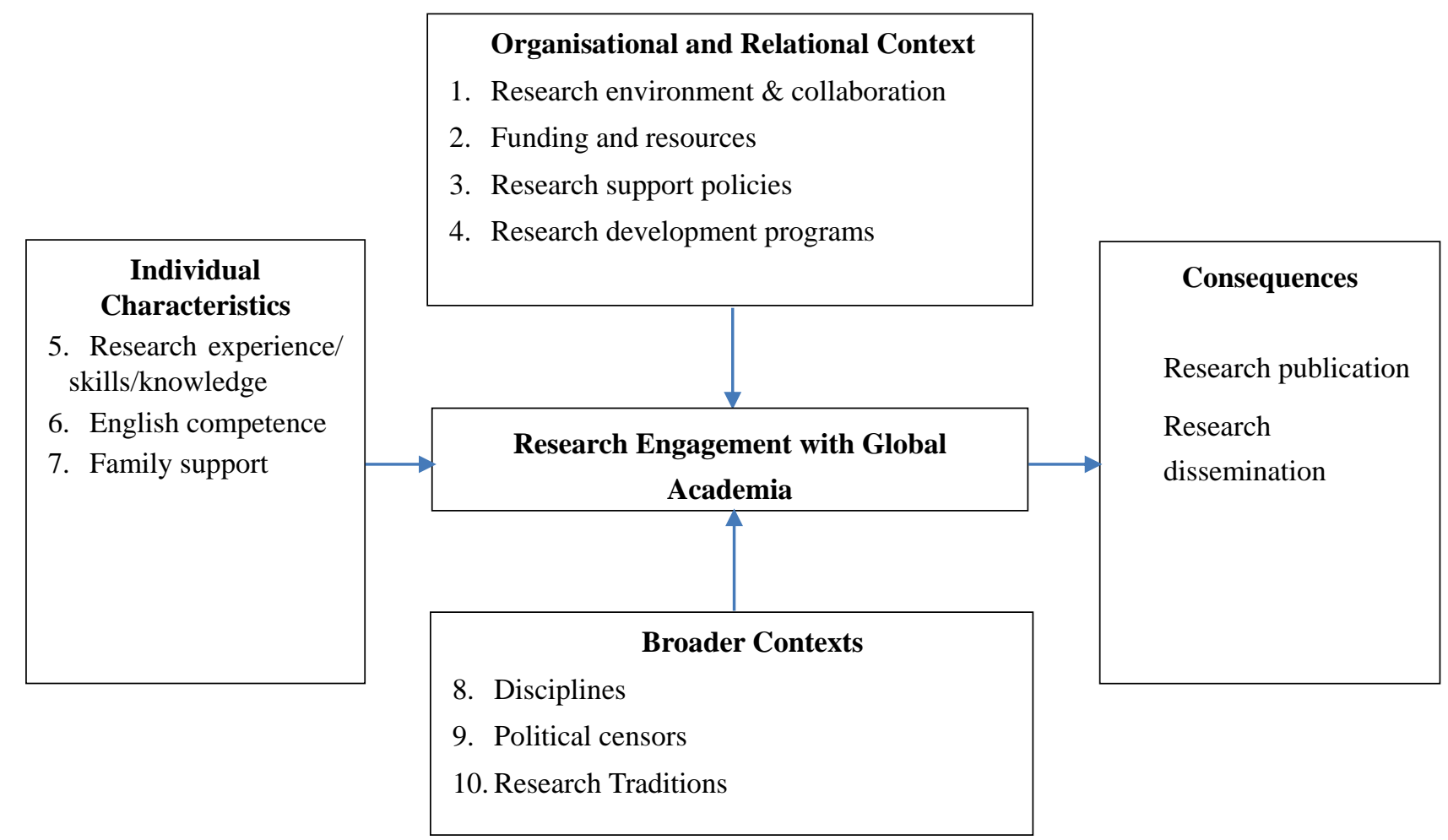

Figure 7. A Proposed Framework to Understand the Engagement with Global Academia by Local Social Science Researchers 
As discussed in the findings, these interwoven factors played a significant role in scholars' research engagement with global academia, positively or negatively influencing their research outcomes. Findings suggest that VSSRs have the desire to engage with the global academia yet the challenges stopped them doing so. Interestingly, many major barriers were reported to come from organisational and relational as well as broader factors rather than from individual factors. In other words, sometimes it might not be the limits of their English or the limited research capacity that blocked many participants from what they wanted to do. For instance, the results suggest that the underdeveloped environment for researchers and the lack of supportive policy for researchers in social science were substantial challenges. The participants did not receive support from their employers and their peers, and thus they might not have had a community in which they could participate, and where they could collaborate with and learn from other researchers. As such, they might not have known how to improve their professional development or to organise a community of practice to position themselves in a friendly research environment. On a broader scale, issues such as the influence of a socialist orientation to social science, or the complex history of social science development (see Section 2) also create various challenges for VSSRs. The findings resonate with Altbach's claim that for some particular fields in humanities and social sciences such as politics and history, the research topics remain 'largely nationally based' (Altbach, 2004, p. 16) and thus integration in global academia is much more challenging in these fields.

The findings show the attempts and desire of VSSRs to engage with the outside world and become a part of the global academic community. They support the claim that knowledge, in this globalised world, is globally and locally shared and the interconnected relationship between global and local knowledge is becoming stronger. The exchange of knowledge occurs in various platforms and contexts. However, the study shows various potential disadvantages that local researchers often have to cope with when interacting with global academia. As can be seen, apart from individual factors such as English capacity and research skills, local researchers are also disadvantaged when not receiving organisational and institutional support. Therefore, the study suggests that the interaction between the local (Vietnam) and the global academia might still be occurring in accordance with the global knowledge penetration mode ( $\mathrm{Li}$ et al., 2006) rather than under a more productive mode of interaction like local-global knowledge bending or local-global knowledge integration. In other words, the hierarchy between the two systems is still inherent and local researchers are disadvantaged.

The importance of $\mathrm{AE}$ has been locally and internationally recognised. Following previous research in the field, this study has identified that the interaction between the global and local knowledge manifests the hierarchy between global and local knowledge - local researchers are somewhat disadvantaged in the process of integration with global academia. In the context of Vietnam, VSSRs have to cope with various local barriers to participate in international research projects and disseminate their research in international conferences or publish their research outcomes in peer-reviewed journals. The study suggests that further research should be undertaken to understand the in-depth personal experience of local researchers when conducting research in the global and local contexts and the role of institutional and organisational factors in supporting local researchers.

\section{Acknowledgements}

The research was funded by Monash International Postgraduate Research Scholarship, Monash Graduate Scholarship, and Monash Postgraduate Publications Award. The authors sincerely thank Monash University for the financial support during the study. We would also like to express our deep gratitude to Dr Jill Brown from Monash Education and Dr Hiep-Hung Pham, Center for Research and Practice on Education, Phu Xuan University for their helpful comments and constructive feedback.

\section{References}

Akpan, W. (2011). 'Local' knowledge, 'global' knowledge, 'development' knowledge: Finding a new balance in the knowledge power play. South African Review of Sociology, 42(3), 116-127. https://doi.org/10.1080/21528586.2011.621244

Altbach, P. G. (2004). Globalisation and the university: Myths and realities in an unequal world. Tertiary Education \& Management, 10(1), 3-25. https://doi.org/10.1080/13583883.2004.9967114

Altbach, P. G. (2013). The international imperative in higher education. Boston: Sense Publishers.

Bathelt, H., Malmberg, A., \& Maskell, P. (2004). Clusters and knowledge: Local buzz, global pipelines and the process of knowledge creation. Progress in Human Geography, 28(1), 31-56. https://doi.org/10.1191/0309132504ph469oa

Clammer, J. (2000). Cultural studies/Asian studies: Alternatives, intersections, and contradictions in Asian social science. Southeast Asian Journal of Social Science, 28(1), 47-65. 
https://doi.org/10.1163/030382400X00163

Gerke, S., \& Evers, H.-D. (2006). Globalizing local knowledge: Social science research on Southeast Asia, 1970-2000. SOJOURN: Journal of Social Issues in Southeast Asia, 1-21. https://doi.org/10.1353/soj.2006.0004

Gough, N. (2002). Thinking/acting locally/globally: Western science and environmental education in a global knowledge economy. International Journal of Science Education, 24(11), 1217-1237. https://doi.org/10.1080/09500690210136620

Harris, L. R., \& Brown, G. T. L. (2010). Mixing interview and questionnaire methods: Practical problems in aligning data. Practical Assessment, Research \& Evaluation, 15(1), 1-14. https://doi.org/10.7275/959j-ky83

Hébert, Y., \& Abdi, A. A. (2013). Critical perspectives on international education. In A. A. Abdi, \& Y. M. Hébert (Eds.), Critical Perspectives on International Education (pp. 1-41). Rotterdam: Sense Publishers.

Hien, P. D. (2010). A comparative study of research capabilities of East Asian countries and implications for Vietnam. Higher Education, 60(6), 615-625. https://doi.org/10.1007/s10734-010-9319-5

Ho, T. T. (1987). Vietnam: Social sciences and the government. In I. Narain (Ed.), Social sciences and the government: The Asian scene (1st ed., pp. 136-140). New Delhi: Lancer International in association with the Association of Asian Social Science Research Councils.

Hoang, C. H. (2021). Glocal production of knowledge: Exploring Vietnamese scholars' perception of 'good' research. Compare: A Journal of Comparative and International Education. https://doi.org/10.1080/03057925.2021.1884046

Hoang, C. H., \& Nguyen, C. D. (2021). Multilingual sources used for research dissemination: Positioning of Vietnamese researchers. International Journal of Multilingualism. https://doi.org/10.1080/14790718.2021.1879811

Hoang, C. H., \& Turner, M. (2020). Framing Vietnamese scholars' negotiation of knowledge production: A $\begin{array}{llll}\text { positioning } & \text { perspective. }\end{array}$ https://doi.org/10.1080/03050068.2020.1771871

Lam, A. (2011). What motivates academic scientists to engage in research commercialization: 'Gold', 'ribbon' or 'puzzle'? Research Policy, 40, 1354-1368. https://doi.org/10.2139/ssrn.1815238

Li, S., Easterby-Smith, M., Lyles, M. A., \& Clark, T. (2006). Tapping the power of local knowledge: A local-global interactive perspective. Journal of World Business, 51(4), 641-653. https://doi.org/10.1016/j.jwb.2016.04.001

London, J. (2013). Making social sciences matter: The status of the social sciences in Vietnam. Paper presented at the Engaging with Vietnam Conference, Thai Nguyen, Vietnam.

Lord, M. D., \& Ranft, A. L. (2000). Organizational learning about new international markets: Exploring the internal transfer of local market knowledge. Journal of International Business Studies, 31(4), 573-589. https://doi.org/10.1057/palgrave.jibs.8490923

Nguyen, T. L. H. (2020). A review of university research development in Vietnam from 1986 to 2019. In H. L. Phan \& N. B. Doan (Eds.), Higher education in market-oriented socialist Vietnam (pp. 63-86). Cham: Palgrave Macmillan

Patton, M. Q. (2002). Qualitative research \& evaluation methods (3rd ed.). Thousand Oaks, CA: Sage Publications.

Perkmann, M., Salandra, R., Tartari, V., McKelvey, M., \& Hughes, A. (2021). Academic engagement: A review of the literature 2011-2019 (Vol. 50). https://doi.org/10.2139/ssrn.3461621

Renn, J. (2012). Survey: The place of local knowledge in the global community. In J. Renn (Ed.), The globalization of knowledge in history (pp. 369-397). Berlin: Edition Open Access.

Selvadurai, S., Choy, E. A., Maros, M., \& Abdullah, K. (2013). Shifting discourses in social sciences: Nexus of knowledge and power. Asian Social Science, 9(7), 97-106. https://doi.org/10.5539/ass.v9n7p97

Tartari, V., \& Breschi, S. (2012). Set them free: Scientists' evaluations of the benefits and costs of universityindustry research collaboration. Industrial and Corporate Change 21(5), 1117-1147. https://doi.org/10.1093/icc/dts004

Tartari, V., Perkmann, M., \& Salter, A. (2014). In good company: The influence of peers on industry engagement 
by academic scientists. Research Policy 43(7), 1189-1203. https://doi.org/10.2139/ssrn.1598456

Tauxe, C. S. (2009). Local science vs. global science: Approaches to indigenous knowledge in international $\begin{array}{llll}\text { development. American } & \text { Anthropologist, } & 111(1), & 122-123 .\end{array}$ https://doi.org/10.1111/j.1548-1433.2009.01087_12.x

Turpin, T., Zhang, J. A., Burgos, B. M., \& Wasantha, A. (2015). Southeast Asia and Oceania. In S. Schneegans (Ed.), UNESCO science report, towards 2030 (pp. 693-732). Paris: UNESCO.

Vaismoradi, M., Turunen, H., \& Bondas, T. (2013). Content analysis and thematic analysis: Implications for conducting a qualitative descriptive study. Nursing \& Health Sciences, 15(3), 398-405. https://doi.org/10.1111/nhs.12048

Vuong, Q.-H., La, V.-P., Vuong, T.-T., Ho, M.-T., Nguyen, H.-K. T., Nguyen, V.-H., . . Ho, M.-T. (2018). An open database of productivity in Vietnam's social sciences and humanities for public use. Scientific Data, 5, 180188. https://doi.org/10.1038/sdata.2018.188

Vuong, Q.-H., Napier, N. K., Ho, T. M., Nguyen, V. H., Vuong, T.-T., Pham, H. H., \& Nguyen, H. K. T. (2019). Effects of work environment and collaboration on research productivity in Vietnamese social sciences: Evidence from 2008 to 2017 scopus data. Studies in Higher Education, 44(12), 2132-2147. https://doi.org/10.1080/03075079.2018.1479845

Warren, D. M., Brokensha, D., \& Slikkerveer, L. J. (1991). Indigenous knowledge systems: The cultural dimension of development. Kegan Paul International. https://doi.org/10.3362/9781780444734.007

\section{Copyrights}

Copyright for this article is retained by the author(s), with first publication rights granted to the journal.

This is an open-access article distributed under the terms and conditions of the Creative Commons Attribution license (http://creativecommons.org/licenses/by/4.0/). 